\title{
Using a convolution integral model for assessing pesticide dissipation time at the end of catchments in the Great Barrier Reef Australia
}

\author{
R. Smith, R. Turner, S. Vardy and M. Warne \\ Department of Environment and Resource Management, Brisbane, Queensland \\ Email: rachael.smith@derm.qld.gov.au
}

\begin{abstract}
A model based on convolution integrals derived from a pesticide application function and the firstorder kinetic decay function (Cook et al. 2011a) was applied to pesticide monitoring data collected from end-of-system (EOS) sites, i.e. on the catchment scale above the tidal zone. The convolution model, at the catchment scale, is based on the summation of pulse inputs over an application period within a catchment area, followed by a period of concentration decay. This model has previously been successfully applied at the block, multi-block and multi-farm scales to predict the concentrations of pesticide lost from runoff. Here we investigate the applicability of the model to determine pesticide concentrations at the catchment scale. The model was applied to atrazine and diuron concentration data collected over the 2010-2011 wet season from three EOS sites (Barratta Creek, Pioneer River and Sandy Creek) that discharge into the Great Barrier Reef lagoon. Temporal trends observed in atrazine and diuron concentrations, fitted the convolution integral model for these catchments. Multiple 'decay events' were observed at each catchment, indicating periods of reapplication throughout the wet season. For each 'decay event', the dissipation half-life $\left(d_{1 / 2}\right)$ was estimated as well as a global $d_{1 / 2}$ representative of the whole wet season. The results indicated that the dissipation half-life of atrazine and diuron at the catchment scale was much shorter than what has previously been observed at the paddock and farm scale. The results presented here will be of value to pesticide runoff models that use an up-scaling approach from paddock scale point models to catchment scale models.
\end{abstract}

Keywords: Pesticides, catchment, half-lives, Great Barrier Reef, dissipation 


\section{INTRODUCTION}

Poor water quality in Great Barrier Reef catchments is of concern due to their proximity to critically important near-shore habitats such as fringing reefs, mangroves, soft-bottom communities and seagrasses (Haynes and Michalek-Wagner, 2000). Studies indicate that pesticides used in the agricultural industry have been transported in runoff from paddocks to many of the rivers and creeks that drain directly into the GBR lagoon (Davis et al., 2008; Mitchell et al., 2005; Packett et al., 2009). Evidence of their fate has been reported in a number of studies demonstrating their presence in offshore flood plumes and therefore pose a risk to reef biota (Shaw and Müller, 2005; Lewis et al., 2009).

The Australian and Queensland governments implemented the Reef Water Quality Protection Plan 2009 (Reef Plan) to improve water quality transported to the GBR. This included implementing agricultural management practices to reduce sediment, nutrient and pesticide loads in runoff from agricultural regions. A target was set in 2009, to be reached by 2013, to reduce the loads of photosystem II (PSII) herbicides (atrazine, diuron, ametryn, hexazinone and tebuthiuron) to the reef by $50 \%$. To assess the performance of the agricultural management initiatives to achieve the Reef Plan's targets modelling tools in combination with water quality monitoring were required (Carroll et al., 2011). Water quality monitoring on its own would not accurately quantify when such short-term targets were met due to climatic conditions influencing the year to year variability in loads (see Bainbridge et al, 2009 for a more detailed explanation). Thus models have been implemented in accordance with Reef Plan to determine reductions in PSII herbicide loads based on land use activities through an upscaling approach, i.e. developing paddock scale point models to generate pesticide loads and applying these to a catchment scale model. Pesticide decay rates are then required to reflect in stream dissipation processes through the catchment.

End-of-system (EOS) pesticide monitoring has been implemented since 2009 to provide concentration and load data for model validation. Smith et al (2011) recently reported the degree of contamination of PSII herbicides across a number of catchments in the GBR catchment area. One key concern was the constant presence of atrazine and the high concentrations of diuron in Barratta and Sandy creeks and Pioneer River, which frequently exceeded the ANZECC and ARMCANZ (2000) water quality guideline trigger values. Both of these PSII herbicides have also been found in the GBR lagoon (Shaw and Müller, 2005; Lewis et al., 2009).

Recently Cook et al (2011a) developed a pesticide fate model to derive half-lives of chemicals based on a convolution integral model which could be applied to concentration data from monitoring studies. The concept of the model was to provide a solution for up-scaling pesticide concentrations from the paddock scale to the catchment scale. The model is based on the premise that pesticide application at the paddock scale occurs in pulses within a catchment over a period of time. Thus pesticide concentration in the surface soil will not be homogenous across the catchment due to the timing of application and initiation of decay. Pesticide concentrations at the EOS are therefore a factor of the heterogeneous timing of pesticide application across blocks and the pesticide half-life that is unique to each catchment, i.e. the dissipation half-life. Cook et al (2011a) suggested that the model could be used to determine the dissipation half-life from monitoring data. Using the dissipation half-life has an advantage over using laboratory derived half-lives (which are often used in runoff modelling tools) as the dissipation half-life is specific to the catchment's conditions and therefore provide a more accurate estimate. To date this model has been used on runoff from the block $\left(\sim 0.0018 \mathrm{~km}^{2}\right)$, multi-block $(\sim$ $\left.0.535 \mathrm{~km}^{2}\right)$ and multi-farm $\left(\sim 29.65 \mathrm{~km}^{2}\right)$ scales (Cook et al $\left.2011 \mathrm{~b}\right)$; here we examine the application of such a model at the catchment scale $\left(326-1488 \mathrm{~km}^{2}\right)$.

The objectives of this study were to determine the following:

i. Does the convolution integral model from Cook et al (2011a) fit pesticide concentration data from the catchment scale, i.e. EOS sites above the tidal zone; and,

ii. What are the dissipation half-lives of diuron and atrazine in the Barratta Creek, Pioneer River and Sandy Creek catchments?

\section{METHODS}

\section{Monitoring}

Samples were collected from EOS sites of three catchments: Sandy Creek (Plane Catchment) and Pioneer River (Pioneer Catchment) in the Mackay-Whitsundays Natural Resource Management (NRM) 
region, and Barratta Creek (Haughton Catchment) in the Burdekin NRM. The catchments above these sites are relatively small, i.e. 326,1488 and $753 \mathrm{~km}^{2}$ (respectively) compared to other catchments in the GBR catchment area (e.g. $>100000 \mathrm{~km}^{2}$ ), have a high proportion of the catchment area under sugar cane farming and drain into the GBR lagoon. The PSII herbicides, diuron and atrazine, are also known to occur in these catchments (Smith et al., 2011).

Grab samples (1 L) were collected over the 2010-2011 wet season. All samples were chemically analysed by Queensland Health Forensic and Scientific Services (QHFSS), a National Association of Testing Authorities (NATA) accredited laboratory. All samples were analysed by high performance Liquid Chromatography Mass Spectrometry /Mass Spectrometry (see Smith et al., 2011 for detailed methods of chemical analyses).

\section{Convolution Integral Model}

Temporal diuron and atrazine concentration data collected at the EOS sites were used to assess the convolution model. Details of the convolution model can be found in Cook et al. (2011a,b), only details specific to this study are described here. Temporal concentration data were visually assessed for trends indicating the convolution phase or the exponential decay phase (see Figure 1). Concentrations in the exponential decay phase (termed here as a 'decay event' i.e. after the pesticide application period has ceased and prior to the next application period) were used to calculate the pesticide half-life according to Cook et al. (2011b). A log linear regression model was applied to the data to calculate a rate constant (a) of the exponential decay curve. The slope was then used to calculate the half-life $\left(t_{1 / 2}\right)$ according to Equation 5 in Cook et al. (2011b):

$$
t_{1 / 2}=\frac{-\ln (2)}{a}
$$

The $95 \%$ confidence intervals (CI) were also calculated from the regression model as well as an $\mathrm{R}^{2}$ value to establish a goodness of fit. In addition, to the 'decay events', a global half-life was also calculated. The global half life is the representative dissipation half-life of each pesticide in each catchment above the sampling site. It is the culmination of multiple 'decay events' that have occurred over the whole wet season due to multiple pesticide application periods. The global half-life was calculated by normalising concentration data to the first recorded concentration in the exponential decay phase for each 'decay event'. The normalised concentrations from all 'decay events' were then combined and this data set was used to calculate a global half-life. The half-lives calculated in this study were defined as a dissipation half-life $\left(d_{1 / 2}\right)$ as other factors in addition to chemical decay would influence the decrease in concentration at the catchment scale, e.g. dilution, leaching and biological breakdown (Capel and Larson, 2001). In the work undertaken by Cook et al. (2011a,b) the half-life was defined as being due only to decay and will be referred to in this paper as the pesticide half-life.

\section{Loads calculation}

Pesticide loads were calculated by the following equation:

$$
\text { Load }=\int_{n}^{0}\left(\text { flow } \times e^{m x+b}\right) d x
$$

Where, flow is the measured discharge $(\mathrm{L} / \mathrm{s}), x$ is time (seconds) from the first recorded concentration of the exponential decay curve, and $\mathrm{m}$ and $\mathrm{b}$ are the slope and intercept calculated from the log linear regression model fitted to measured concentration data.

\section{RESULTS AND DISCUSSION}

Concentrations of atrazine and diuron monitored at the three EOS sites exhibited a fit to the convolution model with first order decay kinetics. Figure 1 demonstrates the two phases of the model depicted by trends in atrazine and diuron concentrations at Barratta Creek: (A) the convolution phase during which pesticide application is occurring over the catchment; and (B) the exponential decay phase which corresponds with the start of the wet season (denoted by an increase in discharge) when atrazine and diuron concentrations follow a first order exponential decay. The decrease in pesticide concentration was shown to continue over a number of runoff events which are characterised by the sharp rise and fall in discharge, as shown in Figure 1. 


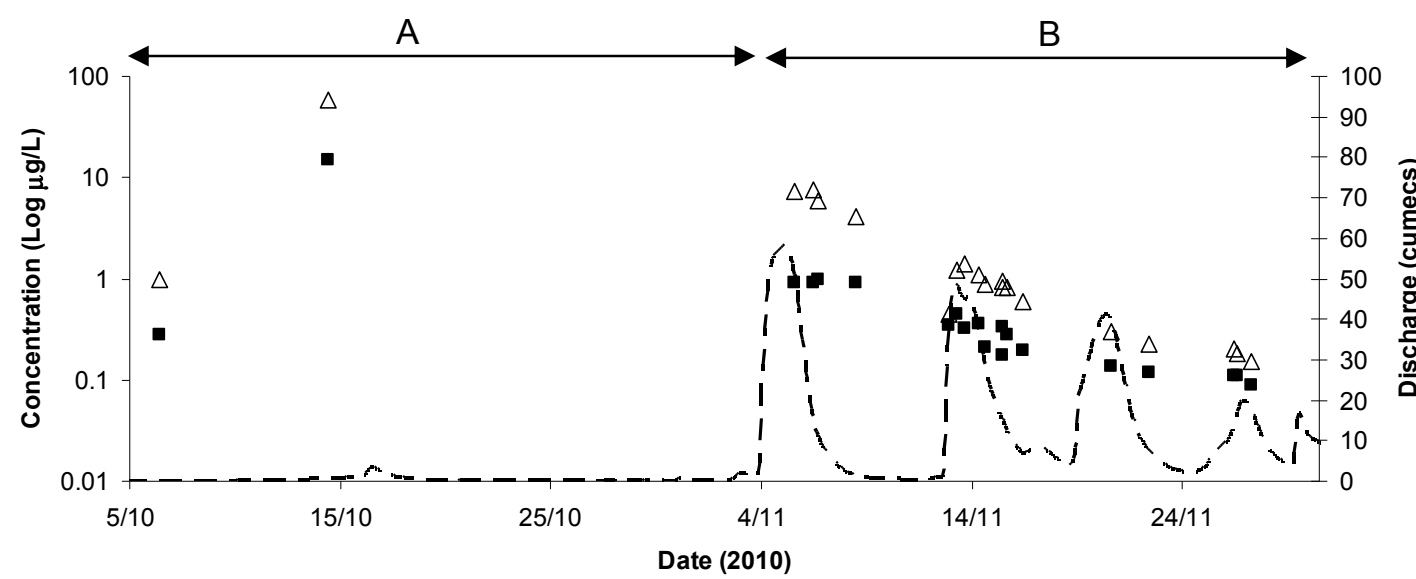

Figure 1: Diuron $(\boldsymbol{\square})$ and atrazine $(\triangle)$ concentration trends at Barratta Creek at the start of the 2010 2011 wet season. (A) indicates the convolution phase, (B) indicates the exponential decay phase, and the dotted line indicates discharge.

Similar trends were demonstrated at Pioneer River (Figure 2). In this scenario, concentrations initially increased with flow signifying the mixing of a more highly concentrated surface runoff with stream base flow until the atrazine concentration reached a maximum. The mixing phase was followed by a first order exponential decay in concentration likely to be due to processes of dissipation (e.g. hydrolysis, photolysis, biological breakdown, adsorption to sediment, dilution; (Capel and Larson, 2001), and which was independent of flow. In addition, multiple 'decay events' were recorded throughout the wet season for each site. For example, Figure 2 depicts the second 'decay event' for the 2010-2011 wet season in the Pioneer River. The additional increases in pesticide concentrations are likely to be linked with secondary pesticide applications after the commencement of the wet season.

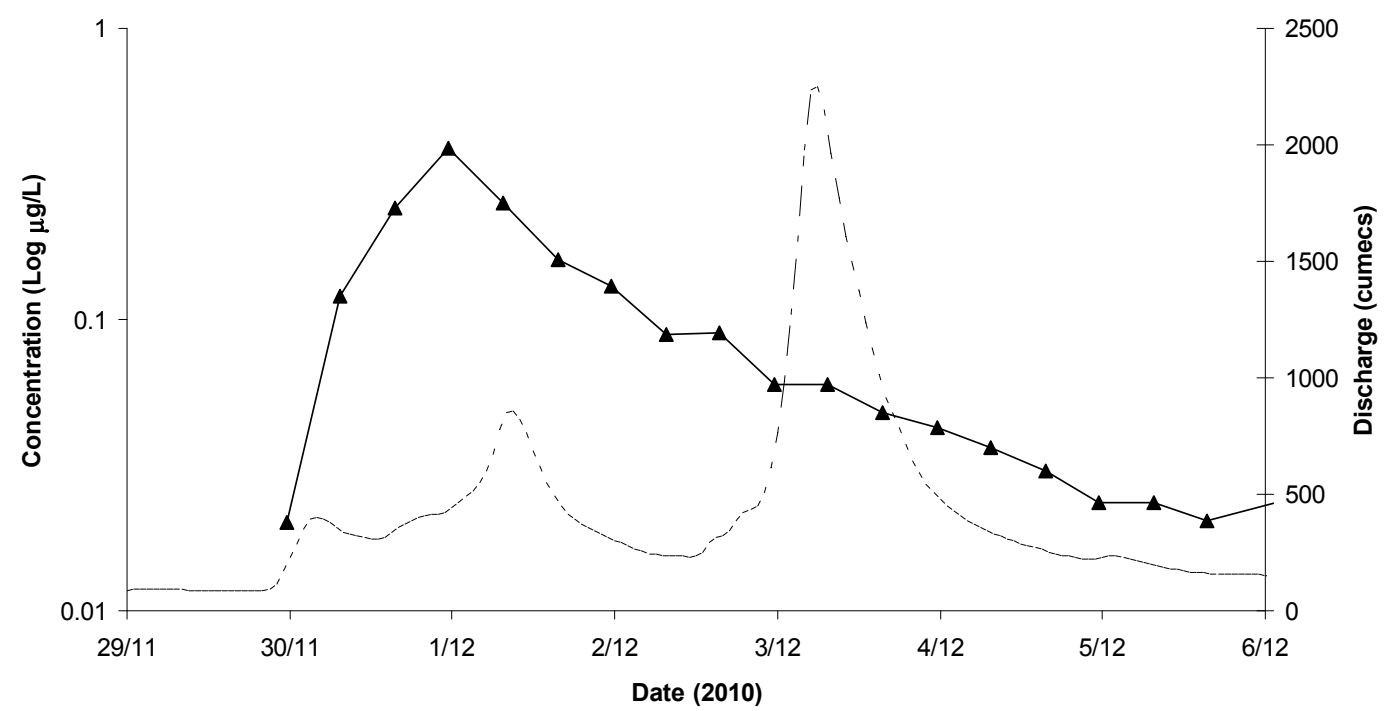

Figure 2: An atrazine $(\boldsymbol{\Delta})$ 'decay event'. Atrazine concentrations from samples collected from the Pioneer River compared to discharge (dotted line).

The decrease in concentration over time was shown to fit very well to the proposed model and therefore provided a reliable estimate of $d_{1 / 2}$. Figure 3 shows diuron concentrations (on a log scale) in the exponential decay phase of one 'decay event', at Barratta Creek, with a fitted log linear regression model and 95\% confidence limits (CIs). Results from the regression analysis indicated that the model accounted for over $90 \%$ of the variation in the data $\left(\mathrm{R}^{2}=0.91\right)$. The ability to reliably fit a regression model to monitoring data has another advantage; it could help plan future sampling design to reduce 
sample numbers without compromising pesticide load calculations. For example, diuron loads did not differ significantly (i.e. were within the 95\% CIs) when the sample number was reduced from 19 to 10 and then to 7 (Table 1).

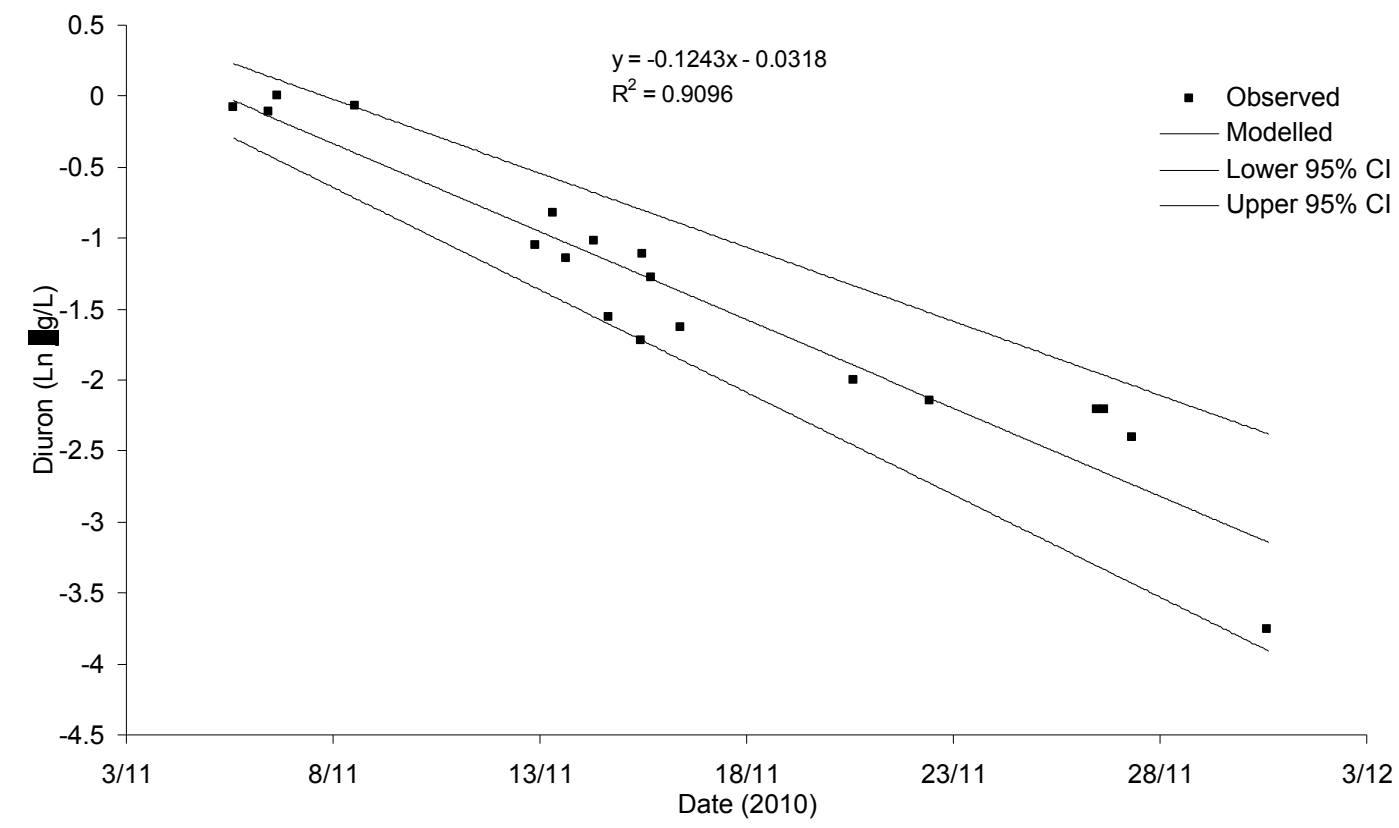

Figure 3: Log linear regression model (solid line) with upper and lower 95\% CIs (dotted lines), and observed diuron concentrations ( $\boldsymbol{\square})$ collected from Barratta Creek.

Table 1: Comparison of diuron loads from Barratta Creek to demonstrate the ability to predict loads using smaller sample numbers based on the concentration fit to a log linear regression model.

\begin{tabular}{cccc}
\hline No. of samples & Calculated load $(\mathbf{k g})$ & Lower $\mathbf{9 5 \%}$ CI & Upper 95\%CI \\
\hline 19 & 8.37 & 5.62 & 12.64 \\
10 & 7.93 & 4.39 & 14.77 \\
7 & 7.88 & 3.12 & 21.50 \\
\hline
\end{tabular}

A log linear regression model was fitted to concentration data for each 'decay event' from each catchment and to the normalised data that represented the whole wet season (global event). The samples collected covered three 'decay events' at Barratta Creek and Pioneer River, whereas samples only covered two 'decay events' at Sandy Creek. For the three EOS sites, the $d_{1 / 2}$ of atrazine and diuron were calculated, along with the upper and lower $95 \%$ CIs and $\mathrm{R}^{2}$ values (Table 2 ). The $\mathrm{R}^{2}$ values indicated that, in the majority of cases, there was a good fit of the regression model to the data $\left(\mathrm{R}^{2}>\right.$ $0.7)$ and therefore provided reliable estimates of $d_{1 / 2}$. The $d_{1 / 2}$ of atrazine ranged from $1.4-5.3$ days, and the $d_{1 / 2}$ of diuron was $1.7-7.7$ days.

The $95 \%$ CIs allowed for an assessment of significant difference between $d_{1 / 2}$ values; i.e. $d_{1 / 2}$ was considered significantly different $(\mathrm{P} \leq 0.05)$ if the $95 \%$ CIs did not overlap. The global $d_{1 / 2}$ was compared to the $d_{1 / 2}$ of the corresponding 'decay events' and in most cases there was no significant difference, indicating that the global $d_{1 / 2}$ estimate was representative of the whole wet season (Table 2). There were significant differences for both the diuron and atrazine global $d_{1 / 2}$ with the corresponding $d_{1 / 2}$ of the second 'decay event' at Barratta Creek and Pioneer River, and the $d_{1 / 2}$ of the third 'decay event' for atrazine at Pioneer River. In all cases where a significant difference occurred, the $d_{1 / 2}$ of the 'decay event' was shorter than the $d_{1 / 2}$ of the global event. Therefore, in these cases using a global $d_{1 / 2}$ value in modelling could overestimate the pesticide loads during some periods of the wet season but would still be a better estimate than a laboratory derived half-life. The global $d_{1 / 2}$ of atrazine and diuron were also fairly consistent across catchments. The atrazine global $d_{1 / 2}$ estimates were not significantly different $(\mathrm{P}>0.05)$ between the three catchments. The global $d_{1 / 2}$ of diuron was greater at Barratta Creek compared to Pioneer River and Sandy Creek, but was only significantly $(\mathrm{P} \leq 0.05)$ greater than the global $d_{l / 2}$ estimated at Pioneer River. 
The catchment $d_{1 / 2}$ estimates presented here were combined with those calculated from pesticide concentrations in runoff from the block, multi-block and multi-farm scales at Sandy Creek (Cook et al. $2011 \mathrm{~b})$. The combined data supported the conclusion of Cook et al. (2011b) that there was a negative correlation between pesticide half-life with area scale. For example, as the scale area increased from block to multi-block, and multi-farm $\left(0.0018-29.65 \mathrm{~km}^{2}\right)$, the corresponding half lives were 36,9 , and 9 days, respectively for atrazine, and 14,7 , and 10 days respectively for diuron. As the pesticides moved from the paddock through the catchment, the decrease in dissipation time was likely to be due to the interaction of the pesticide with additional factors that accelerate dissipation e.g. dilution, hydrolysis and biological breakdown (Capel and Larson, 2001).

Table 2: Dissipation half-lives (days) at Barratta Creek, Pioneer River and Sandy Creek calculated using a log linear regression model. Dissipation half-lives $\left(d_{1 / 2}\right)$ were calculated for individual 'decay events' and as a 'global' $d_{1 / 2}$. In parentheses: lower and upper 95\% confidence intervals expressed as a range and the coefficient of determination $-\mathrm{R}^{2}$.

\begin{tabular}{|c|c|c|c|c|c|}
\hline Site & Herbicide & \multicolumn{3}{|c|}{ 'Decay event' $d_{1 / 2}$ (days) } & Global $d_{1 / 2}$ (days) \\
\hline $\begin{array}{l}\text { Barratta Ck } \\
\left(753 \mathrm{~km}^{2}\right)\end{array}$ & Diuron & $\begin{array}{c}5.6 \\
(4.8-6.6 ; 0.91)\end{array}$ & $\begin{array}{c}2.4 \\
(1.8-3.9 ; 0.78)\end{array}$ & $\begin{array}{c}7.6 \\
(5.5-13.0 ; 0.54)\end{array}$ & $\begin{array}{c}6.9 \\
(5.3-9.8 ; 0.50)\end{array}$ \\
\hline \multirow{2}{*}{$\begin{array}{l}\text { Pioneer } \mathbf{R} \\
\left(1488 \mathrm{~km}^{2}\right)\end{array}$} & Atrazine & $\begin{array}{c}2.6 \\
(2.3-3.0 ; 0.95)\end{array}$ & $\begin{array}{c}1.4 \\
(1.2-1.8 ; 0.87)\end{array}$ & $\begin{array}{c}1.4 \\
(1.0-2.4 ; 0.72)\end{array}$ & $\begin{array}{c}3.5 \\
(2.7-5.2 ; 0.46)\end{array}$ \\
\hline & Diuron & $\begin{array}{c}3.0 \\
(2.6-3.6 ; 0.93)\end{array}$ & $\begin{array}{c}1.7 \\
(1.4-2.0 ; 0.93)\end{array}$ & $\begin{array}{c}1.9 \\
(1.3-3.3 ; 0.70)\end{array}$ & $\begin{array}{c}3.6 \\
(2.9-4.7 ; 0.62)\end{array}$ \\
\hline $\begin{array}{l}\text { Sandy Ck } \\
\left(326 \mathrm{~km}^{2}\right)\end{array}$ & Diuron & \multicolumn{2}{|c|}{$\begin{array}{c}3.6 \\
(2.8-5.1 ; 0.77)\end{array}$} & $\begin{array}{c}7.7 \\
(4.6-23.9 ; 0.49)\end{array}$ & $\begin{array}{c}4.3 \\
(3.4-5.9 ; 0.67)\end{array}$ \\
\hline
\end{tabular}

\section{CONCLUSION}

Pesticide concentration data collected from EOSs were fitted with the convolution integral model described by Cook et al. (2011a \& b). The results that have been presented here demonstrate that $d_{1 / 2}$ estimates can be calculated from monitoring data at EOS sites which provide a value specific for that catchment. The results also agree with Cook et al. (2011b) that with the movement of pesticides to the end of catchments, $d_{1 / 2}$ decreases. This information will be valuable for modellers who use an upscaling approach (from paddock to catchment) to predict pesticide loads being transported to the Great Barrier Reef. Secondly this work will provide estimates of half lives required by the catchment models to model in stream dissipation processes. The results presented here may also aid in designing future pesticide sampling programs for EOS sites to reduce sample numbers without compromising the accuracy of load calculations.

\section{ACKNOWLEDGEMENTS}

We are very grateful to a number of people who helped with the collection of flow data and grab samples in the regional areas. This included the regional hydrographers, Hydrographic Support Unit, and Regional NRM bodies. The study was funded as part of the Queensland Government's commitment to the joint Australian and Queensland Government "Paddock to Reef Integrated Monitoring, Modelling and Reporting Program" which was established in order to measure progress towards the Reef Plan (2009) water quality goals and targets.

\section{REFERENCES}

ANZECC and ARMCANZ (2000). Australian and New Zealand Guidelines for Fresh and Marine Water Quality, Vol. 1. The Guidelines, Australian and New Zealand Environment and Conservation Council and Agriculture and Resource Management Council of Australia and New Zealand.

Bainbridge, Z.T., Brodie, J.E., Lewis, S.E., Waterhouse, J.E. and Wilkinson, S.N. (2009b). Utilising catchment modelling as a tool for monitoring Reef Rescue outcomes in the Great Barrier Reef catchment area. In Anderssen, R.S., R.D. Braddock and L.T.H. Newham (eds) 18th World IMACS Congress and MODSIM09 International Congress on Modelling and Simulation. Modelling and Simulation Society of Australia and New Zealand and International Association for Mathematics and Computers in Simulation, pp. 3301-3307, July 2009. 
Smith et al., Using a convolution integral model for assessing pesticide dissipation time ...

Carroll, C., Waters, D, Vardy, S., Silburn D.M., Attard, S., Thorburn P.J., Davis, A.M., Halpin, N., Schmidt, M., Wilson, B., and Clarke, A. (2011). A paddock to reef monitoring and modelling framework for the Great Barrier Reef. Paddock and catchment component. Agriculture Environment and Ecosystems (in press).

Capel, P.D. and Larson, S.J. (2001). Effect of scale on the behaviour of atrazine in surface waters. Environmental Science and Technology, 35, 648-656.

Cook, F.J., Knight, J.H., Silburn, D.M., Kookana, R.S. and Thorburn, P.J. (2011a). Upscaling from paddocks to catchments of pesticide mass and concentration in runoff. Agriculture Environment and Ecosystems (in press).

Cook, F.J., Rohde, K.W. and Silburn, D.M. (2011b). Pesticide transport in runoff comparison with convolution model for Mackay Whitsunday region. MODSIM11 paper.

Davis, A., Lewis, S., Bainbridge, Z., Brodie, J., Shannon, E., 2008. Pesticide residues in waterways of the lower Burdekin region: challenges in ecotoxicological interpretation of monitoring data. Australasian Journal of Ecotoxicology, 14, 89-108.

Haynes D., Michalek-Wagner, K., 2000. Water Quality in the Great Barrier Reef World Heritage Area: Past Perspectives, Current Issues and New Research Directions. Marine Pollution Bulletin, 41, 428434.

Lewis, S.E., Brodie, J.E., Bainbridge, Z.T., Rohde, K.W., Davis, A.M., Masters, B.L., Maughan, M., Devlin, M.J., Müller, J.F., Schaffelke, B., 2009. Herbicides: A new threat to the Great Barrier Reef. Environmental Pollution, 157, 2470-2484.

Mitchell, C., Brodie, J., White, I., 2005. Sediments, nutrients and pesticide residues in event flow conditions in streams of the Mackay Whitsunday Region, Australia. Marine Pollution Bulletin, 51: 23-36.

Packett, R., Dougall, C., Rohde, K., Noble, R., 2009. Agricultural lands are hot-spots for annual runoff polluting the southern Great Barrier Reef lagoon. Marine Pollution Bulletin, 58, 976-986.

Shaw, M., Müller, J.F., 2005. Preliminary evaluation of the occurrence of herbicides and PAHs in the Wet Tropics region of the Great Barrier Reef, Australia, using passive samplers. Marine Pollution Bulletin, 51, 876-881.

Smith, R., Middlebrook, R., Turner, R., Huggins, R., Vardy, S. and Warne, M. (2011). Large-scale pesticide monitoring across Great Barrier Reef Catchments - Paddock to Reef Integrated Monitoring and Modeling Program. Marine Pollution Bulletin (in press). 